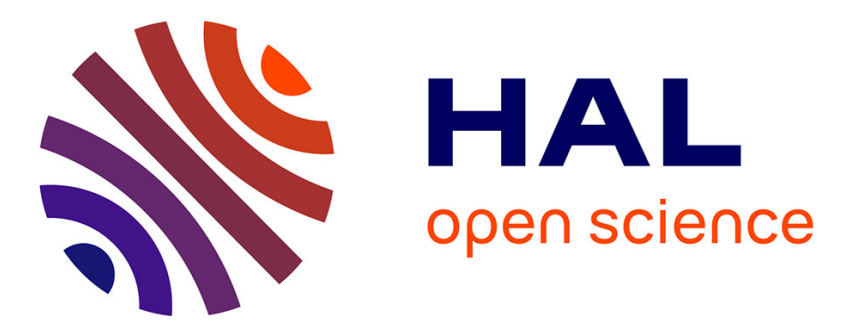

\title{
Comparison of direct-drive PM generators for tidal turbines
}

\author{
Sofiane Djebarri, Jean Frédéric Charpentier, Franck Scuiller, Mohamed \\ Benbouzid
}

\section{- To cite this version:}

Sofiane Djebarri, Jean Frédéric Charpentier, Franck Scuiller, Mohamed Benbouzid. Comparison of direct-drive PM generators for tidal turbines. IEEE PEAC 2014, IEEE, Nov 2014, Shanghai, China. pp.474-479, 10.1109/PEAC.2014.7037902 . hal-01120831

\section{HAL Id: hal-01120831 \\ https://hal.science/hal-01120831}

Submitted on 26 Feb 2015

HAL is a multi-disciplinary open access archive for the deposit and dissemination of scientific research documents, whether they are published or not. The documents may come from teaching and research institutions in France or abroad, or from public or private research centers.
L'archive ouverte pluridisciplinaire HAL, est destinée au dépôt et à la diffusion de documents scientifiques de niveau recherche, publiés ou non, émanant des établissements d'enseignement et de recherche français ou étrangers, des laboratoires publics ou privés. 


\section{Comparison of Direct-Drive PM Generators}

\section{for Tidal Turbines}

\author{
Sofiane Djebarri ${ }^{1,2}$, Jean Frederic Charpentier ${ }^{1}$, Franck \\ Scuiller ${ }^{1}$ \\ ${ }^{1}$ French Naval Academy, EA 3634 IRENav \\ Brest, France \\ Email: sofiane.djebarri@ecole-navale.fr
}

\author{
Mohamed Benbouzid ${ }^{2}$ \\ ${ }^{2}$ University of Brest, EA 4325 LBMS \\ Brest, France \\ Email: Mohamed.Benbouzid@univ-brest.fr
}

\begin{abstract}
The aim of the paper is to compare the design of direct-drive permanent-magnet (PM) generators associated with horizontal axis tidal turbines. The turbine/generator couplings are examined. These turbine/generator couplings consist of a POD and Rim-driven assembly. In a Rim-Driven association the electrical generator active parts are inserted in a duct surrounding the blades. For POD generator insertion, the electrical machine is placed in a nacelle located on the turbine axis. To achieve the generators sizing, a design rated point related to an industrial MCT is defined. The used design models include an electromagnetic model which is linked to a thermal model in an optimization procedure that goals to minimize the active parts cost. Firstly, a single rotor/single stator PM axial flux generator and a radial flux PM generator are designed for a rimdriven MCT specification. For these generators sizing, a comparison of the machines active parts and the machines geometrical dimensions are carried out. Secondly, radial flux PM generators are designed for Rim-Driven and POD assembly and a comparison is performed for this study case. Finally, the influence of the POD diameter on the generator electromagnetic design is studied. It shows that the active parts costs are minimized, when the generator diameter is around $1 / 3$ of the turbine diameter for the considered specifications. These performed comparisons between the considered study cases aims to help designers in their technologies choices.
\end{abstract}

Keywords-Marine Current turbine, POD, Rim-Driven, PM Generators

\section{INTRODUCTION}

Direct driven PM generators are relevant solution for marine and offshore energy applications because they allow minimizing the maintenance operations on the systems. In direct driven systems, generator is operated at low speed (typically lower than 50rpm). In one hand, the elimination of the gearbox leads to an improvement of efficiency and a minimization of maintenance [1]. In the other hand the low speed generator is characterized by a high torque. This high torque level is related to high active parts volume (iron, magnets, copper).

Several hydrodynamic principles are used in the major current projects [2]: horizontal [3-5] or vertical axis turbines or with oscillating hydrofoils [6]. These solutions can be

This work was supported by French Navy and ECA-EN Company associated with geared systems or direct driven systems [6]. The developed solutions are all at a TRL level between 5 and 7 and reference solutions have not already been determined at the industrial level. This is why it is necessary to investigate the pro and the cons of the possible technological solutions.

The presented work presents elements of comparison for several direct driven generators for horizontal axis turbine. The possibility to locate the generator in a duct which surrounds the turbine (rim driven system) like in the Open Hydro project or in [3] (Fig. 1) is compared to the more classical solution where generator is located in a pod located in the turbine axis (fig.2) like in the Atlantis Project or the abandoned ALSTOM Beluga 9 project [5], [7].

In the first case, the internal radius of the generator is equal to the external radius of the turbine blades. In the second case, the external radius of the generator is limited to avoid too strong disturbance in the flow in the turbine disk.

For these two configurations, two kinds of electromagnetic structures for direct driven generator are considered: axial flux and radial flux PM machines. The presented work presents rough design of such kinds of generator for a common operating point and a similar turbine. This operating point is near of operating points used for some major industrial projects. The objective is to give comparison elements and main trends on possible technological choices for direct driven generators.

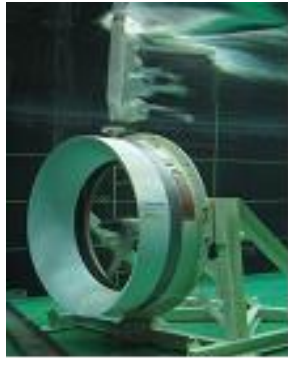

(a)

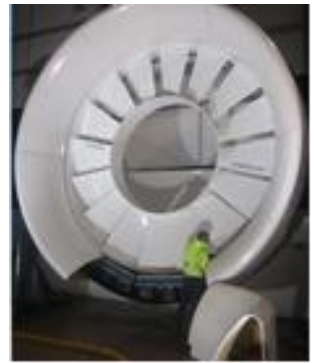

(b)
Fig. 1. Rim-Driven experimental turbine IRENav (a), Open Hydro RimDriven (b) [4]. 


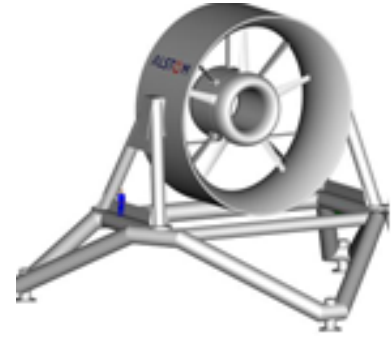

(a)

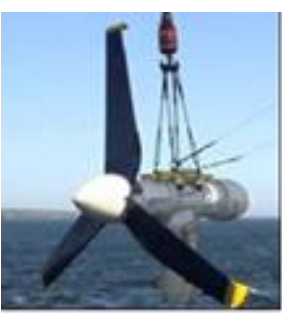

(b)
Fig. 2. POD type turbine [5], [7]: «BELUGA 9» ALSTOM (a), «AR$1000 »$ (Atlantis ressources corporation) (b).

\section{Design Methodology}

\section{A. Used Methods and Specifications}

The aim of the study is to compare and evaluate several topologies of tidal current generator in the EM structure point of view (axial and radial flux ) and in terms of assembly point of view (rim-driven or pod assembly). The design methodology couples an EM model and a thermal model. These two models are inserted in an optimization process which aims to minimize the active parts cost. Constraints are considered in the optimization process. They are related to maximal temperature, minimal efficiency and geometry (internal and external radius and slot shape). The EM model is derived from a 2D model proposed in [8] and solves the governing field equations by separating the polar variables. This EM model allows the calculation of the dimensions and performance of the generator from EM material characteristics (saturation level of soft materials, magnet magnetization) and operating point specifications. The thermal model, is mainly similar to the model presented in [9], and allows checking that the temperature does not exceed a maximal limit. Common data are used. They relate to slot filling factor, to winding topology (diametral windings), to ambient temperatures and to active material characteristics. Common site and turbine specifications are also used. A specific tidal speed is determined from tidal current speed statistics on a typical tidal spot. A typical optimal turbine power coefficient corresponding to an optimal Tip Speed Ratio (TSR) is fixed (these data are related to turbine hydrodynamic performance). With the knowledge of the turbine diameter, these data allows defining a characteristic rotating speed and corresponding power which corresponds to the common design operating point which is used in all the studied cases for the generator designs. This common data and specifications allow making relevant comparison between the studied design options. These data are summarized in table I and table II. The comparison results are related to the global active part cost and mass. A scheme of the association of the models and optimization method is given at Fig. 3.

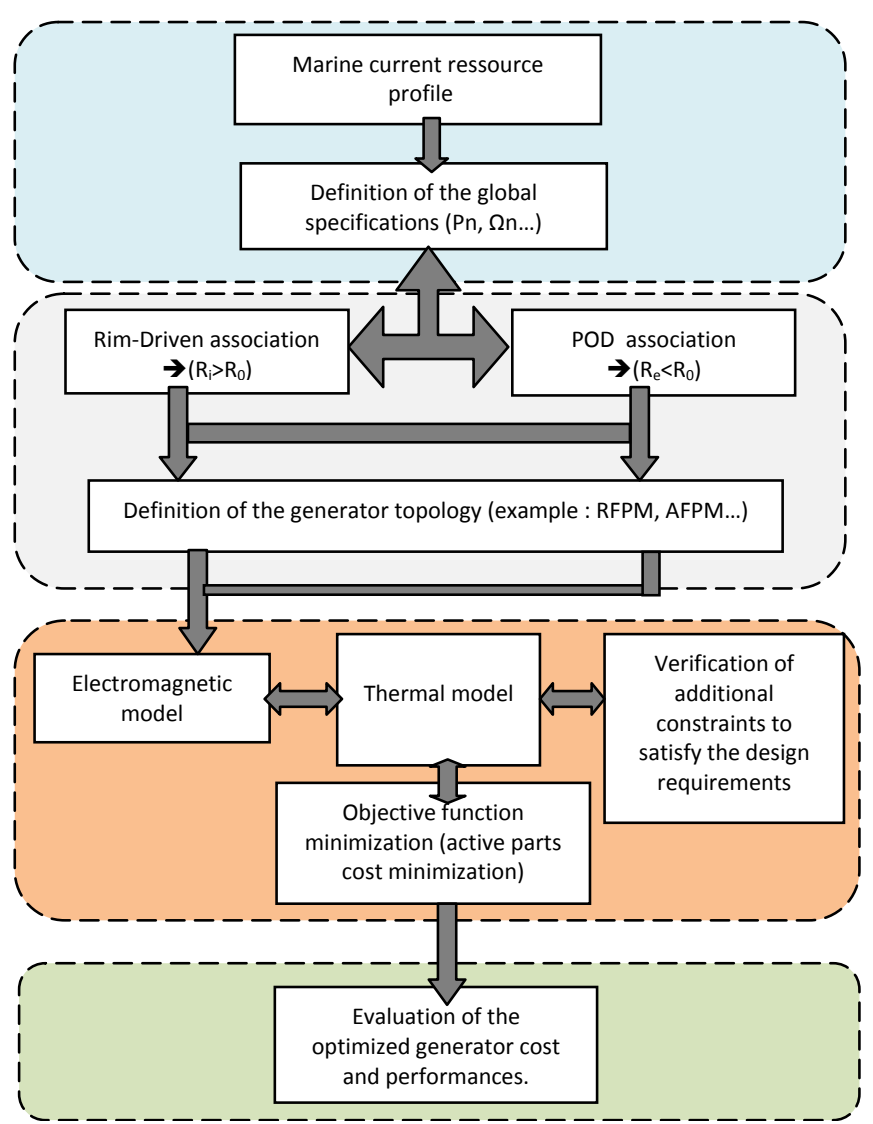

Fig. 3. Models and methods association.

TABLE I. COMMON DESIGN DATA FOR THE EM STRUCTURES.

\begin{tabular}{|l|l|l|l|}
\hline Maximum tooth height to tooth width ratio & $\mathfrak{R}_{\max }$ & 10 & - \\
\hline Minimum tooth height to tooth width ratio & $\mathfrak{R}_{\min }$ & 4 & - \\
\hline $\begin{array}{l}\text { Relative air gap thickness related to air gap } \\
\text { diameter }(D)\end{array}$ & $k$ & $2 \%$ o & - \\
\hline Air gap & $h_{g}$ & $k . D$ & $\mathrm{~mm}$ \\
\hline $\begin{array}{l}\text { Angular shift between EMF and currents (MTPA } \\
\text { sinusoidal control of stator currents) }\end{array}$ & $\psi$ & 0 & $\mathrm{rad}$ \\
\hline Phase number & $m$ & 3 & - \\
\hline Number of slot per pole and per phase & $S_{p p}$ & 1 & - \\
\hline End winding length [10] & $L_{e w}$ & $\pi D / 2 p$ & $\mathrm{~m}$ \\
\hline Slot filling factor & $k_{f}$ & 0.65 & - \\
\hline Relative magnet width (relative to the pole width) & $\beta_{m}$ & 0.66 & - \\
\hline Maximal copper temperature & $T_{\max }$ & 100 & ${ }^{\circ} \mathrm{C}$ \\
\hline Minimal electrical efficiency & $\eta_{e ́ l e c}$ & 0.90 & - \\
\hline Sea water temperature & $T_{\text {water }}$ & 30 & ${ }^{\circ} \mathrm{C}$ \\
\hline
\end{tabular}

TABLE II. ACTIVE PARTS CHARACTERISTICS AND COSTS

\begin{tabular}{|l|l|l|l|}
\hline \multicolumn{4}{|c|}{ Permanent magnets $\left(\mathbf{N}_{\mathbf{d}} \mathbf{F}_{\mathbf{e}} \mathbf{B}\right)[11]$} \\
\hline Magnetization & $B_{r}$ & 1.22 & $\mathrm{~T}$ \\
\hline Coercitive field & $H_{c j}$ & 1208 & $\mathrm{kA} / \mathrm{m}$ \\
\hline Maximal temperature & - & 100 & ${ }^{\circ} \mathrm{C}$ \\
\hline density & & 7400 & $\mathrm{~kg} / \mathrm{m}^{3}$ \\
\hline cost [11] & $C_{\text {magnets }}$ & 115 & $\$ / \mathrm{kg}$ \\
\hline
\end{tabular}




\begin{tabular}{|c|c|c|c|}
\hline \multicolumn{4}{|c|}{ Iron laminations $\mathrm{F}_{\mathrm{e}} \mathrm{S}_{\mathrm{i}}\left(3 \%\right.$ to $3.5 \%$ of $\left.\mathrm{S}_{\mathrm{i}}\right)[12]$} \\
\hline Operating electrical frequency & $f_{\text {elec }}$ & 50 to 400 & $\mathrm{~Hz}$ \\
\hline Saturation level & $B_{\text {sat }}$ & 1.48 & $\mathrm{~T}$ \\
\hline Maximal field density & - & 2.2 & $\mathrm{~T}$ \\
\hline Lamination thickness & - & 0.1 & $\mathrm{~mm}$ \\
\hline Specific losses $(50 \mathrm{~Hz})$ & $P_{\mathrm{FeO}}$ & 5 & $\mathrm{~W} / \mathrm{kg}$ \\
\hline Relative permeability & - & 5000 & - \\
\hline Density & $\rho_{\mathrm{FeSi}}$ & 7700 & $\mathrm{~kg} / \mathrm{m}^{3}$ \\
\hline cost [12] & $C_{\text {lam }}$ & 1 & $\$ / \mathrm{kg}$ \\
\hline \multicolumn{4}{|c|}{ Copper $\left(20^{\circ} \mathrm{C}\right)$} \\
\hline Electric resistivity & $\rho_{C u}$ & $1.6779 \times 10^{-8}$ & $\Omega . m$ \\
\hline density & & 8960 & $\mathrm{Kg} / \mathrm{m}^{3}$ \\
\hline cost [11] & $C_{\text {copper }}$ & 7.8 & $\$ / \mathrm{kg}$ \\
\hline
\end{tabular}

\section{B. Studied Magnetic Structures}

The axial flux machine under consideration is a mono stator mono rotor structure similar to the one depicted in fig.4 (from [13]). This structure comprises a stator disk which supports windings and a rotor disk supporting magnets. Of course, the active conductors are oriented along radius direction and the magnet flux is oriented in the axial direction. The second structure is a more classical radial flux structure like the one presented in fig. 5. In this structure the active conductors are oriented along the axial direction and the magnet flux along the radial direction. For high diameter generators a hollow center can be used. These two kinds of structure are associated with the studied turbine in pod type assembly or in a rim driven assembly. For instance, Fig. 6 shows a scheme of a radial flux machine in a rim driven turbine.

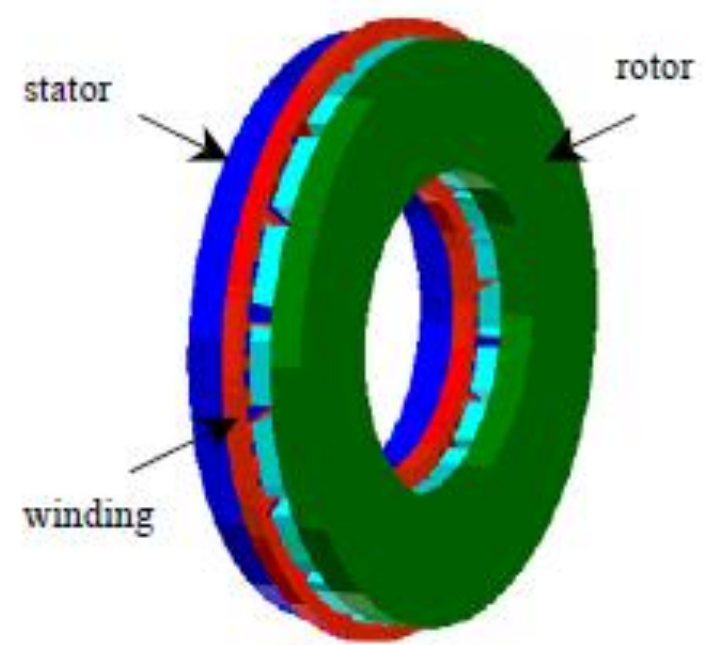

Fig. 4. Basic sketch of a mono stator-mono rotor axial flux machine [13].

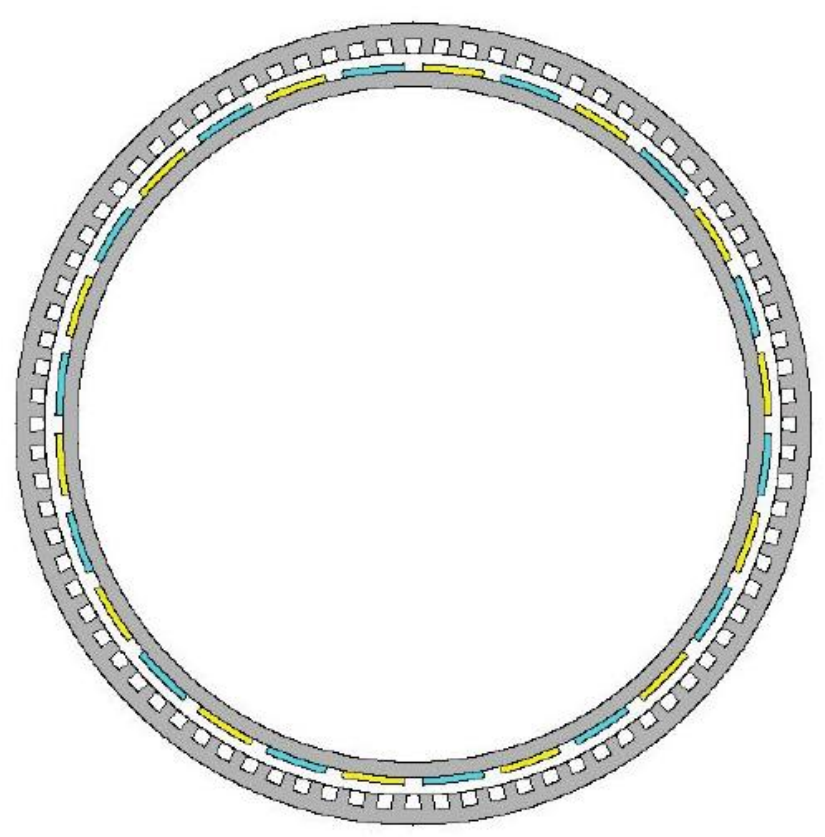

Fig. 5. Radial flux machine sketch.

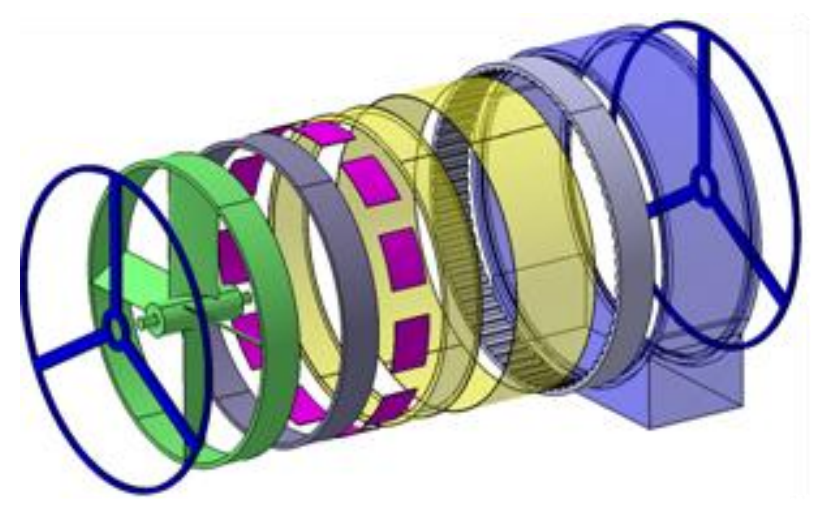

Fig. 6. Basic sketch of a radial flux rim driven generator.

\section{Site and Turbine Characteristics}

The used design operating point relates to a $1 \mathrm{MW}$ turbine located in a high tidal current spot. The operating point corresponds to a tidal current speed of $3.5 \mathrm{~m} / \mathrm{s}$. The studied turbine is characterized by an optimal power coefficient of 0.41 corresponding to a TSR (Tip Speed Ratio) of 6. This value corresponds to a $34 \mathrm{rpm}$ rotating speed and a $1 \mathrm{MW}$ power for a $12 \mathrm{~m}$ turbine diameter. These data are summarized in table III.

TABLE III. OPERATING POINT DATA.

\begin{tabular}{|l|l|l|l|}
\hline Rated value of the water current & $V_{r}$ & 3,5 & $\mathrm{~m} / \mathrm{s}$ \\
\hline Turbine rated power & $\mathrm{P}_{\mathrm{r}}$ & 1000 & $\mathrm{~kW}$ \\
\hline Turbine rated rotating speed & $\Omega_{\mathrm{r}}$ & 34 & $\mathrm{tr} / \mathrm{min}$ \\
\hline Rated torque & $\mathrm{T}_{\mathrm{r}}$ & 280860 & $\mathrm{Nm}$ \\
\hline Turbine diameter & $\mathrm{D}_{0}$ & 12 & $\mathrm{~m}$ \\
\hline
\end{tabular}




\section{RADIAL AND AXIAL FLUX STRUCTURE COMPARISON FOR A RIM DRIVEN TURBINE}

In this section, a radial flux PM (RFM) machine and an axial flux PM (AFM) machine are designed for a Rim-Driven assembly considering the methodology and common specifications described in the previous sections.

Table IV shows the obtained results regarding the geometrical dimensions and the performances.

TABLE IV. MAIN DIMENSIONS AND EM PERFORMANCE OF THE TwO STRUCTURES.

\begin{tabular}{|l|l|l|l|}
\hline \multicolumn{1}{|c|}{ AFM } & \multicolumn{1}{|c|}{ RFM } & m \\
\hline genternal radius of the & 6.0739 & 6.094 & $\mathrm{~m}$ \\
\hline $\begin{array}{l}\text { Average radius of the active } \\
\text { parts (for AFM only) }\end{array}$ & 6.0369 & - & $\mathrm{m}$ \\
\hline $\begin{array}{l}\text { internal radius of the stator } \\
\text { (for RFM only) }\end{array}$ & - & 6.0412 & $\mathrm{~m}$ \\
\hline $\begin{array}{l}\text { Internal generator } \\
\text { radius=turbine external radius }\end{array}$ & 6 & 6 & $\mathrm{~m}$ \\
\hline Active lenght & 7.39 & 7.75 & $\mathrm{~cm}$ \\
\hline Number of pole pairs & 232 & 238 & - \\
\hline Electric efficiency $\left(\eta_{\text {elec }}\right)$ & 0.96 & 0.96 & - \\
\hline Iron losses percentage $\left(P_{f e}\right)$ & 22.17 & 22.87 & $\%$ \\
\hline Joule losses percentage $\left(P_{J}\right)$ & 77.82 & 77.12 & $\%$ \\
\hline $\begin{array}{l}\text { Conductor maximal } \\
\text { temperature }\end{array}$ & 50 & 53.7 & $\%$ \\
\hline $\begin{array}{l}\text { Ratio of the end windings } \\
\text { copper volume on the total } \\
\text { copper volume. }\end{array}$ & 63.45 & 61.88 & $\%$ \\
\hline
\end{tabular}

Figures $7 \mathrm{c}$ and $7 \mathrm{~b}$ show a sketch of a few poles of the two structures (axial view for the RFM and radial view for the AFPM). Figure 7a shows the overall dimensions of the RFM. These 3 figures show the main dimensions of the two structures.

Figures $8 \mathrm{a}$ and $8 \mathrm{~b}$ give the calculated cost and mass for the active parts of the 2 Rim-Driven structures.

As shown in Fig. 8, the cost and mass of the active parts of the two structures are roughly of the same order. The main dimensions of the two structures are similar (Table IV). In the two cases, the structures are characterized by a very small axial length which leads to a very high volume of end windings. The end windings copper represents more than $60 \%$ of the total copper volume. The constraint on efficiency is saturated and the machine remains relatively cold (the maximal temperature is not reached). This thermal behavior is related to the machine immersion which contribute to a very good cooling. This first part of the study shows that AFM and RFM designs are roughly similar. This is why only Radial Flux Machines are considered in the last part of the paper.

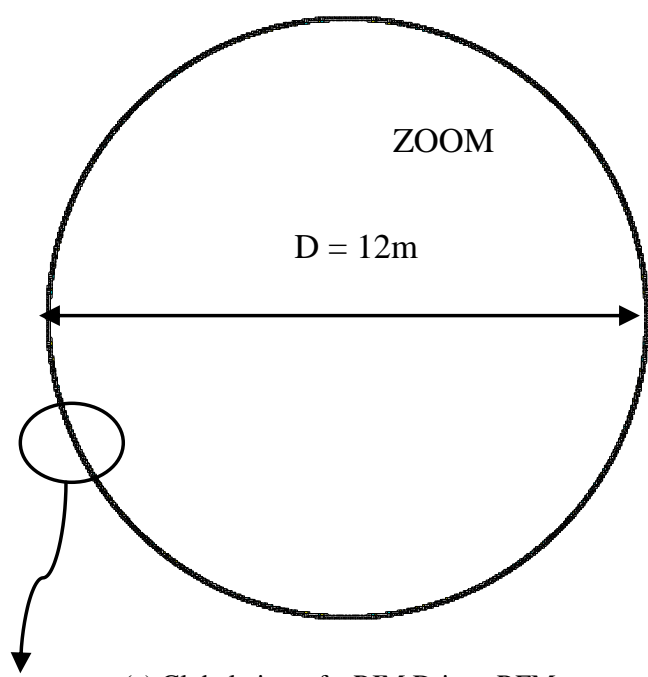

(a) Global view of a RIM Driven RFM.

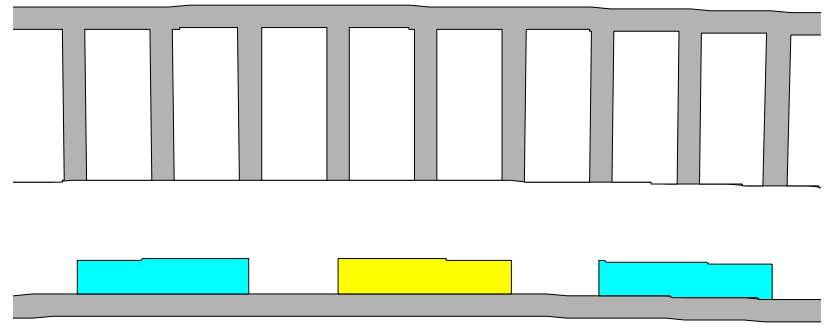

(b) Sketch of 3-poles of Rim-Driven RFM.

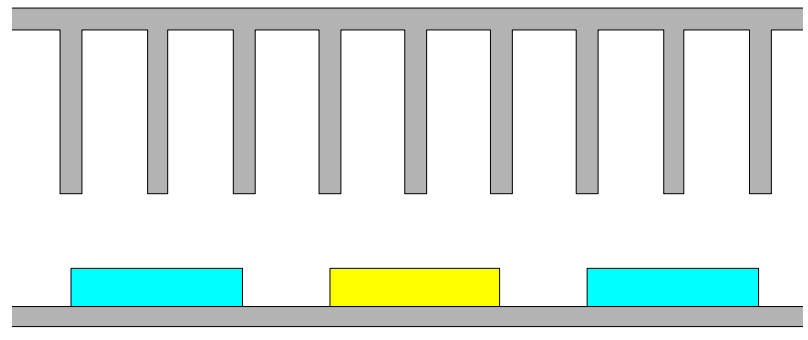

(c) Sketch of 3-poles of Rim-Driven AFM.

Fig. 7. View of the designed structures

\section{COMPARISON BETWEEN POD AND RIM DRIVEN GENERATOR}

In the next part of the paper Rim Driven and Pod association between the specified turbine and a RF generator are studied. In the Rim-Driven case the minimal internal diameter of the generator active parts equals the turbine diameter $\left(D_{\text {in }}=12 \mathrm{~m}\right)$. In the pod case the external diameter of the generator is limited to $1 / 3$ of the turbine generator $\left(D_{\text {ext }}=\right.$ $4 \mathrm{~m})$. The results in terms of cost and mass of active parts for the two configurations are shown in Figs. 9a and 9b. 


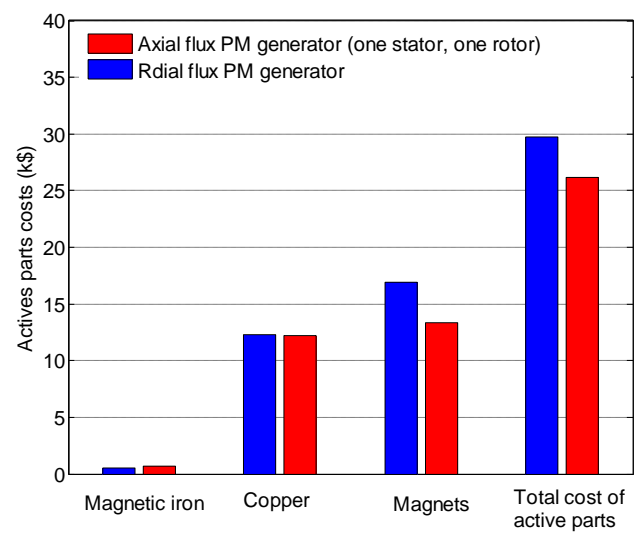

(a)

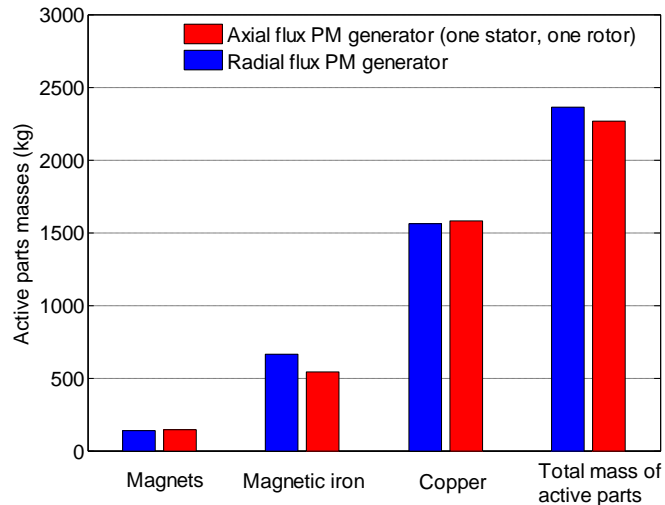

(b)

Fig. 8. Comparison of the 2 structures (a) active part cost, (b) active part mass.

On the first hand, results show that the cost of the POD generator is $20 \%$ lower than the one of the rim driven structure. This point stigmatizes a better use of magnet and copper relative to a higher value of active length. On the other hand, the mass of the pod generator is higher than the one of the rim driven structure. This higher mass is mainly related to iron parts.

In a second step, optimal designs are calculated with different fixed values of maximal radius of the generator to evaluate the influence of this radius on the design. This value is varying between $2 \mathrm{~m}$ and $12 \mathrm{~m}$. It can be noted that the $12 \mathrm{~m}$ value corresponds roughly to a rim-driven configuration and that the values between 7 and $11 \mathrm{~m}$ seem not very realistic in terms of hydrodynamic behavior. The results in terms of cost, mass, active length and pole numbers are presented in Figs. $10 \mathrm{a}$ to $10 \mathrm{~d}$. Figure 10a shows that an optimal value of the external radius which is around $1 / 3$ of the studied turbine diameter leads to a minimal cost of active parts.

Figure 10b shows that upper a given value around $5 \mathrm{~m}$ the mass remains roughly constant. This fact can be explained with the reduction of axial length which leads to higher end windings volume and higher flux leakage phenomenon. A too strong external radius constraint (external diameter lower than $4 \mathrm{~m})$ leads to a strong rise of the cost and mass

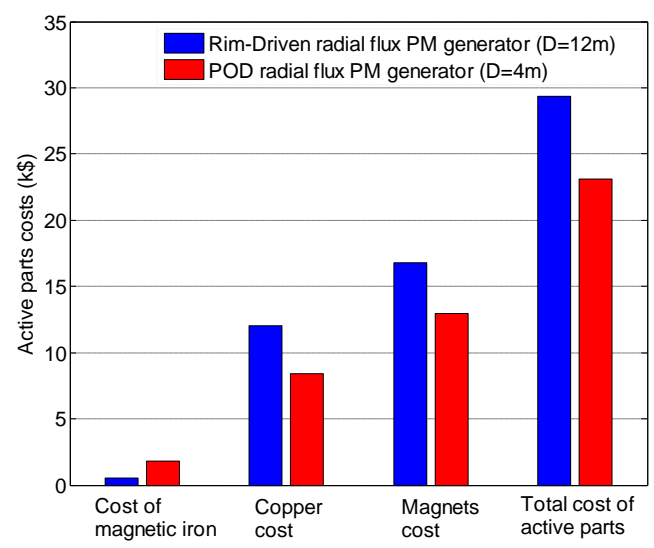

(a)

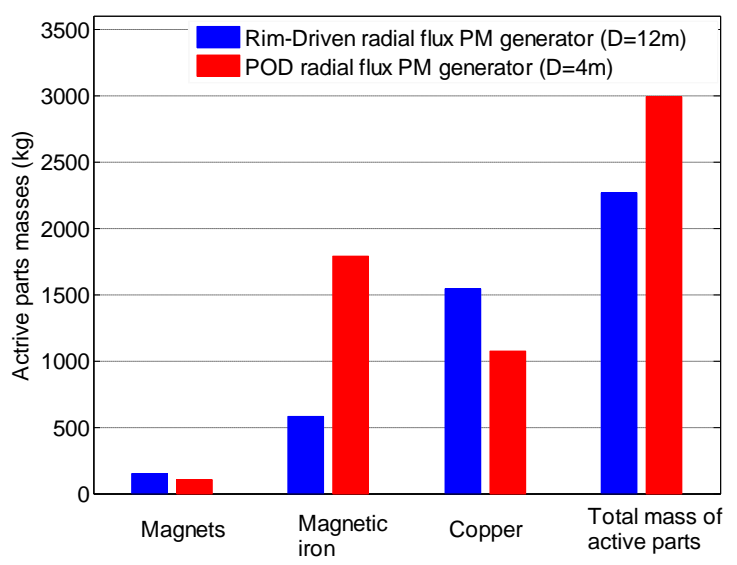

(b)

Fig. 9. Comparison of RFM POD and RD structures: (a) active part cost, (b) active part mass.

Indeed if we consider a given force density $\sigma_{t}\left(\mathrm{~N} / \mathrm{m}^{2}\right)$ in the gap, the torque is directly proportional to the air gap surface and the diameter $\left(T=\frac{1}{2} \sigma_{t} S D\right)$. That means that if end effects and flux leakage effects are neglected the size of the machine is in first order inversely proportional to the diameter as underlined in [3]. This is why a too strong constraint on internal diameter leads to an oversizing of the generator dimensions. In figure $10-\mathrm{d}$ it can be noted that the number of pole pairs increase with the diameter. This phenomenon is related to the fulfillment of a geometrical constraint on the shape of the slots (the ratio between slot height and slot width is limited to a maximal value (Table I).

\section{CONCLUSION}

The presented study focuses on the design of direct driven permanent magnet generators for tidal current turbine. The aim of this study is to bring out comparison elements between several electromagnetic structures and generator/turbine association. 


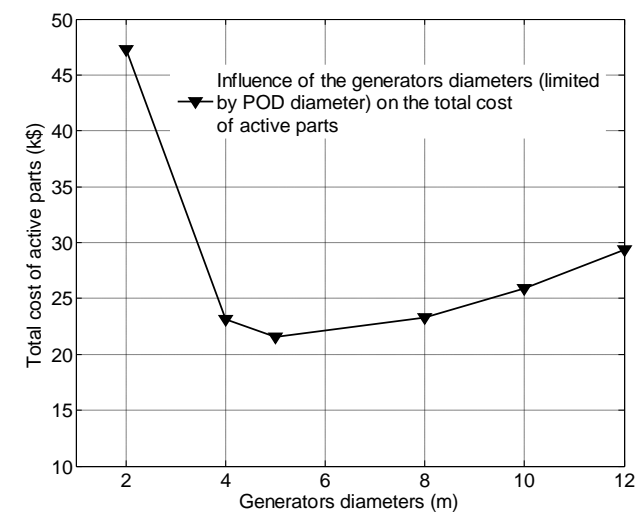

(a)

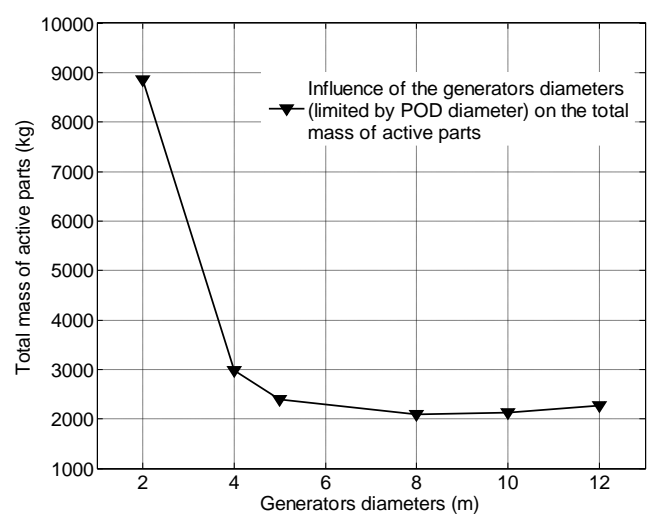

(b)

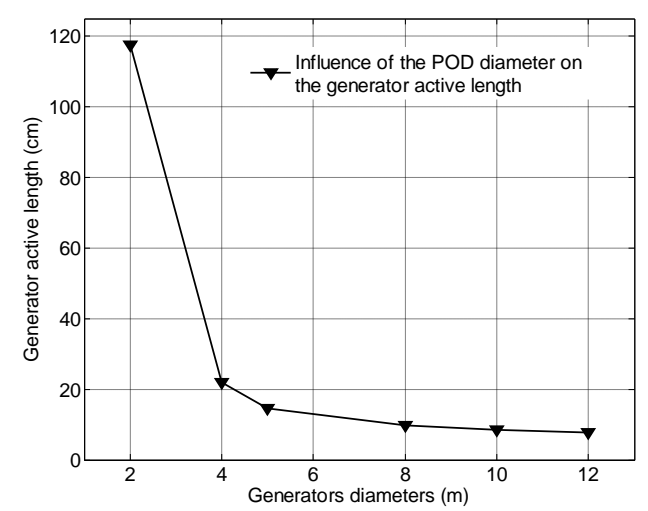

(c)

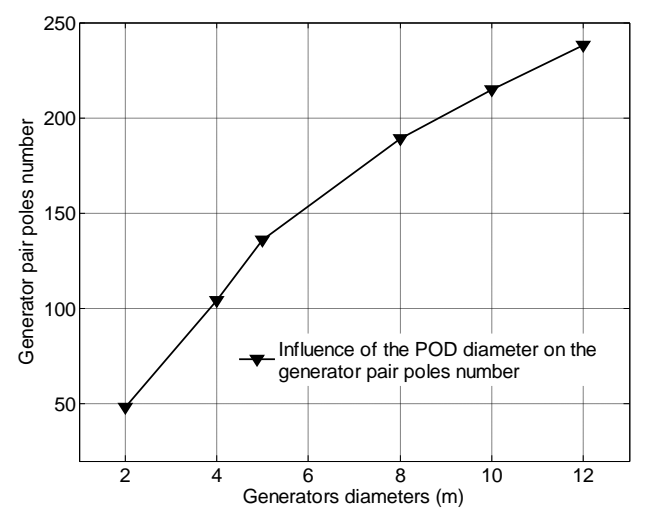

(d)

Fig. 10. POD external diameter influence, (a) active part cost, (b) active part mass, (c) active lenght, (d) pole numbers.
Two electromagnetic topologies are considered: a single rotor/single stator axial flux PM generator and a more classical radial flux generator. Two kind of turbine/generator association are studied: a rim driven system where the generator is included in a duct surrounding the turbine blades and a more classical solution where the generator is located in a pod connected to the turbine shaft. Generator dimensions and performances are calculated for these solutions. These designs correspond to a common rated operating point related to a $12 \mathrm{~m}$ diameter turbine located in a tidal spot with high current values. The design method associates an EM model and a thermal model in an optimization process which aims to minimize the cost of active parts with respect to geometrical, thermal and efficiency constraints. The study shows that the single rotor single stator axial flux machine cost and mass are of the same order than those obtained for a radial flux machine. Considering the turbine/machine association a POD structure where the radius of the generator is limited to $1 / 3$ of the structure is heavier than the Rim Driven solution. However this POD solution will lead to a smaller global cost of the active parts. The study shows that an optimal value of the external radius of the generator can be found which corresponds to mass or cost minimization for each given specification set (rated operating point and given turbine).

\section{REFERENCES}

[1] R.S. Semken, M. Polikarpova, P. Roytta, J. Alexandrova, J. Pyrhonen, J. Nerg, A. Mikkola and J. Backman, "Direct-drive permanent magnet generators for high-power wind turbines: Benefits and limiting factors," IET Renewable Power Generation, vol. 6, n¹, pp. 1-8, 2012.

[2] E. Block, “Tidal power: an update," Renewable Energy Focus, vol. 13, n'5, pp. 20-22, 2012.

[3] L. Drouen, J.F. Charpentier, E. Semail, S. Clenet- "Investigations on the performances of the electrical generator of a rim-driven marine current turbine," in Proceedings of the 2008 ICOE, Brest (France), 6 pp., October 2008.

[4] OpenHydro: http://www.openhydro.com (last accessed January 2014).

[5] P. Gilson, "Alstom's tidal in stream energy converter demonstration project," in Proceedings of the 2011 WREEEC, Bali (Indonesia), October 2011.

[6] S. Benelghali, M.E.H. BenBouzid, J.F. Charpentier , "Marine tidal current electric power generation technology: State of the art and current status," in Proceedings of the 2007 IEEE IEMDC, Antalya (Turkey), vol. 2, pp. 1407-1412, May 2007.

[7] Atlantis ressource corporation: http://atlantisresourcesltd.com (last accessed January 2014).

[8] Z.Q. Zhu, D. Howe, E. Bolte and B. Ackermann, "Instantaneous magnetic field distribution in brushless permanent magnet dc motors, Parts I to IV," IEEE Trans. Magnetics, vol. 29, n¹, pp. 124-158, January 1993.

[9] S. Djebarri, J. F. Charpentier, F. Scuiller, M. Benbouzid, and S. Guemard, "Rough design of a double-stator axial flux permanent magnet generator for a rim-driven marine current turbine," in Proceedings of the 2012 IEEE ISIE, Hangzhou (China), pp. 1450-1455, May 2012.

[10] T.J.E Miller, M.I McGilp, D.A Staton and J.J Bremner, "Calculation of inductance in permanent-magnet DC motors," IEE Proc. Electric Power Applications, vol. 146, n 2, pp. 129-137, March 1999.

[11] www.mineralprices.com (last accessed March, 2013).

[12] www.asianmetal.com (last accessed March, 2013).

[13] M. Aydin, S. Huang and T. A. Lipo "Axial flux permanent magnet disc machines: A review," in Proceedings of the 2004 SPEEDAM, 12pp., Capri (Italy), June 2014 